\title{
Participação social na elaboração e execução do Plano Plurianual de Macapá-AP no período de 2013 a 2016: alguns enunciados a partir do fenômeno
}

\author{
Alexandre Gomes Galindo ${ }^{1}$ e Jawdat Abu-El-Haj ${ }^{2}$ \\ 1 Doutor em Sociologia pela Universidade Federal do Ceará. Docente da Universidade Federal do Amapá. E-mail: alexandregalin- \\ do@bol.com.br \\ 2 Doutor em Ciência Política pela University of California. Docente da Universidade Federal do Ceará. E-mail: jawdatab@gmail.com
}

RESUMO: Este artigo apresenta o resultado do estudo, envolvendo análise documental, entrevistas e observação participante, sobre dinâmicas de participação da sociedade no processo de elaboração/execução do planejamento de Macapá (capital do estado do Amapá), através de um desenho institucional de gestão compartilhada proposto pelo governo que assumiu a administração pública de 2013 a 2016. Evidenciou-se que a criação do Estado do Amapá, em 1988, impulsionou processos de transformação espacial, social, econômica e política, com renovação das elites locais, constatando-se que, em 2013, ocorreram os maiores esforços de mobilização para elaboração compartilhada do planejamento municipal e de alocação de recursos em programas de gestão participativa. O respectivo governo implantou experiências participativas com denominações variadas como "O Povo no Comando", "Congresso do Povo" e "Prefeitura na sua Rua", alterando a abordagem de relacionamento com a sociedade a partir da segunda metade de seu mandato, gerando avanços e empoderamentos, apresentando conflitos, limitações e desafios.

Palavras-Chave: Democracia; Democracia Participativa; Participação; Participação Social; Participação Popular.

Social participation in the preparation and implementation of the multi-annual plan of Macapá-AP in the period from 2013 to 2016: some theses from the phenomenon

ABSTRACT: This article presents the results of a qualitative research that involved document analysis, interviews and observational research about the interaction between civil society members and public authorities in Macapá (the capital of Amapá) by highlighting societal participation during formulation/implementation of municipal planning, through the instituional arrangements of shared management between 2013 and 2016. It affirmed that the creation of the state in 1988 was a hallmark that had profound spatial, economic, political and social impact, especially, through the change of the local political elite. The study documented efforts in 2013 to mobilize and jointly manage participatory planning for the allocation of resources through programs such as: "People in the Command", "Congress of the People", "Municipality in your Street", that altered the relationship between local government-society interaction during the second half of the administration, and produced empowerment but also conflicts, limitations and new challenges.

Keywords: democracy; participatory democracy; participation, social participation; popular participation. 
Este artigo apresenta os resultados de um estudo ${ }^{1}$ desenvolvido com o propósito de perceber as características do processo de interlocução entre integrantes da sociedade civil e o poder público em MacapáAmapá-Brasil, dando relevo à análise das dinâmicas de participação dos munícipes no processo político de elaboração e execução do planejamento municipal, através da implantação de um desenho institucional ${ }^{2}$ de gestão compartilhada proposto pela equipe de governo que assumiu a administração pública durante o período de 2013 a 2016.

A institucionalização de ambientes públicos de integração entre segmentos da sociedade e governo, envolvendo deliberações políticas, ganhou espaço no Amapá a partir de meados da década de 1990, através de debates sobre questões relacionadas ao desenvolvimento sustentável nas áreas ambiental, social e econômica, e, posteriormente, com a disseminação da formação de conselhos de políticas setoriais, da realização de conferências setoriais e da elabora-

\footnotetext{
${ }^{1}$ Para análise mais aprofundada dos resultados obtidos pelo estudo ver Galindo (2017).
}

2 O conceito de Instituições Participativas, proposto por Avritzer (2008, p.45), diz respeito Lato sensu às "formas diferenciadas de incorporação de cidadãos e associações da sociedade civil na deliberação sobre políticas". Nessa perspectiva, elas possuem quatro características principais (AVRITZER, 2009, p. 8): a) a operação simultânea através dos princípios da representação e participação; b) a transformação das características voluntárias de participação da sociedade civil em forma de organização política permanente; c) a interação com partidos políticos e atores estatais; e d) a relevância do desenho institucional para a sua eficácia. No escopo do presente estudo, em conformidade com o sentido mais estrito apresentado por Cortes (2011, p.137), o conceito de Instituições Participativas "se refere a mecanismos de participação criados por lei, emendas constitucionais, resoluções ou normas administrativas governamentais que permitem o envolvimento regular e continuado de cidadãos com a administração pública, tanto diretamente quanto através de representantes". ção participativa de Planos Diretores. Nesse período, de aproximadamente três décadas de emancipação territorial, os esforços para promover a construção de um processo democrático que ampliasse e garantisse espaços participativos de deliberações no estado do Amapá foram mais influenciados pelas induções institucionais do Governo Federal, em função de uma política macro, do que por intenções explícitas geradas por iniciativas próprias dos governos locais. As experiências de participação que foram localmente induzidas estiveram relacionadas principalmente à elaboração participativa de emenda parlamentar, de orçamento municipal e de Plano Plurianual-PPA.

Macapá, capital do Amapá desde 1944, é, atualmente, considerada o principal núcleo populacional, econômico e administrativo com forte poder indutor da condução política no Estado. Desde a criação do Estado, em 1988, a condução política de Macapá passou pela elaboração e execução de Planos Plurianuais desenvolvidos no início de cada mandato dos prefeitos eleitos conforme os ritos institucionais vigentes, havendo forte influência dos aspectos técnicos e da participação dos atores políticos na elaboração desses Planos, em especial os que integravam as esferas administrativas do poder público.

Entretanto, o processo de elaboração do Plano Plurianual de Macapá, em 2013, e sua posterior execução, contou com a participação de uma parcela expressiva de membros da sociedade civil diretamente indicados pelos moradores do município, compondo uma rede de pessoas de diversos segmentos sociais diretamente vinculadas aos processos deliberativos nessa etapa da construção das políticas. Esse processo marcou uma ruptura na forma com que a 
administração pública municipal vinha conduzindo os procedimentos de elaboração do planejamento e da gestão da participação ${ }^{3}$ no desenvolvimento das políticas locais.

Consequentemente, esse trabalho teve a intenção de lançar o olhar sobre as formas e dinâmicas locais de interlocução entre a sociedade e o poder público na condução do projeto político de gestão em Macapá, fundamentada na seguinte pergunta de partida: De que maneira se configurou o processo democrático de participação social na gestão política de Macapá, no período de 2013 a 2016, tendo-se como objeto de análise a elaboração e a execução do Plano Plurianual do Município para o quadriênio 2014-2017?

A presente pergunta de partida agregou as seguintes questões norteadoras que ampararam esforços de pesquisa sob a perspectiva histórica e da política local: De que modo se configura o processo de desenvolvimento do Município de Macapá e de sua elite política local? De que modo o processo de participação social se integra nessa dinâmica de desenvolvimento?

Sob a perspectiva normativa e institucional emergiram três inquietações: De que modo as intencionalidades de implantação

\footnotetext{
${ }^{3}$ Para efeito deste estudo, "Programa de Gestão da Participação" é aquele contido no PPA, cujo objetivo está explicitamente relacionado com o fomento ou realização de ações de participação da sociedade nos processos de elaboração, implantação, controle e/ou avaliação de políticas públicas da Prefeitura Municipal. O termo "traduzido" utilizado neste contexto diz respeito ao estabelecimento de uma relação semântica e pragmática entre programas e ações (projetos e atividades) programadas no PPA com recursos destinados à sua execução futura. Por mais que possam ocorrer ligações semânticas entre princípios, diretrizes e estratégias, a intencionalidade só é pragmaticamente traduzida se houver recursos alocados em programas ou ações no PPA.
}

de um processo participativo de gestão foram integradas ao planejamento dos governos que assumiram a administração pública de Macapá após a criação do Estado do Amapá? De que modo o processo participativo integrou a ideologia, filosofia e plataforma da equipe de governo que assumiu a administração pública de Macapá nos anos de 2013 a 2016? De que modo os membros do governo municipal incorporaram o desenho participativo na estrutura da Prefeitura e nas dinâmicas de elaboração e execução do Plano Plurianual para o quadriênio 2014-2017?

Sob a perspectiva dos atores sociais, duas indagações se fizeram presentes no estudo: De que modo a sociedade civil exerceu autonomia, iniciativa e capacidade de ação perante o poder público no processo de elaboração e execução do plano Plurianual durante o período de 2013 a 2016? Como se configuraram os avanços, apropriações, conflitos, dificuldades e desafios percebidos pelos principais atores que participaram desse processo?

Após esta parte introdutória, o presente artigo inicialmente apresenta uma breve reflexão teórica sobre o processo participativo no estabelecimento da condução política em sociedades democráticas e logo após discorre sobre o caminho metodológico percorrido durante a pesquisa. Em seguida, são apresentados enunciados relacionados aos aspectos contextuais e ao processo de gestão participativa implementado em Macapá no período de 2013 a 2016 e tecidas as considerações finais.

\section{POLÍTICAS PÚBLICAS PARTICIPATIVAS: ORIGENS TEÓRICAS E METODOLÓGICAS.}

Estudos sobre políticas publicas partici- 
pativas tiveram um significativo crescimento desde a década de 1990, movidos pela ascensão da esquerda latino-americana. Precisamente a adoção no Brasil desta linha de governabilidade e seus resultados sociais positivos animaram a esquerda mundial, celebrando este "modo de governar" como o renascimento das forças progressistas após décadas de ostracismo politico e teórico. Uma terceira via se levantava das cinzas para rivalizar com as duas alternativas clássicas, a do welfare State e a dos agentes privados. Estava posicionada para responder à pergunta chave que dominava a agenda de pesquisas desde os anos de 1930: como desenhar políticas governamentais que reconciliem uma cultura democrática, resistente aos encantamentos autoritários, e simultaneamente assegure a oferta equitativa e eficiente de bens públicos?

Até a década de 1990 duas linhas, a do welfare State e a dos agentes privados, dominavam a produção acadêmica e tiveram uma significativa influência no desenho das políticas públicas. A terceira via já existia na academia, porém sem influencia nos círculos governamentais. Essa relação entre a vida académica e práticas políticas é sintomática de estudos de políticas publicas, possuindo três características. Primeiro, intenciona o mapeamento objetivo do poder político e sua repercussão nas expectativas de vida dos diversos segmentos da população. Segundo, a objetividade em identificar os atores do jogo de interesses, o ambiente de interação e seus resultados concretos levou ao surgimento de uma multidisciplinaridade de estudos, englobando uma diversidade de metodologias e teorias advindas das ciências políticas, sociologia, etnografia, economia, estatística, matemática, inteligência artificial, psicologia social, geografia, urbanismo, engenharia etc. Finalmente, apesar da sua elevada objetividade dedutiva (lógico-racional) e indutiva (empírico-descritiva), manifesta-se como a mais normativa das ciências sociais, considerando sua finalidade de promover as liberdades políticas, a igualdade de acesso e a dignidade humana.

Quatro linhas teóricas, entre as décadas de 1930 e 1950, deram a feição original desta disciplina: racionalismo, sistema, institucionalismo e economia neoclássica. Os três primeiros defendiam as instituições governamentais como a esfera de alocação legitima de valores (bens públicos), enquanto a quarta considerava os agentes privados, agindo em mercados competitivos, como a alternativa mais eficiente e justa.

Racionalismo é identificado com a obra de Harold Lasswell (1936), um divisor de águas na analise de política pública. Para Lasswell, duas variáreis determinam o sucesso das políticas públicas numa ordem democrática: a racionalidade administrativa e transparência técnica. Isso se traduz numa padronização dos ciclos de políticas públicas em sete etapas: 1 . Inteligência (coleta de informações), 2. Promoção (ou exploração de diversas opções técnicas disponíveis ao formulador de política), 3. Prescrição (apresentação das soluções adequadas), 4. invocação oficial (formalização da opção escolhida), 5. Aplicação (estabelecimento de regras que premiam e sancionam), 6 . Terminação (finalização da política dentro de prazos específicos) e 7. Avaliação. Esse ciclo original sugerido por Lasswell foi reagrupado, em manuais técnicos da analise política, em cinco fases: 1 . formação de agenda, 2. formulação de política, 3. processo decisório, 4. implementação e 5. avaliação (BARDACH, 2012). 
Enquanto Lasswell considerava a racionalização administrativa como variável determinante da eficiência e legitimidade política, David Easton (1953 e 1965) focava sua atenção no ambiente de organização e agregação de interesses que se processa fora do governo. Recorrendo a uma linguagem derivada da cibernética, Easton estabeleceu quatro processos políticos integrados que hipoteticamente levam à estabilização e reprodução de um sistema político funcional. No primeiro ciclo as mudanças no ambiente sócio-econômico induzem demandas e apoios canalizados às instancias representativas (partidos, grupos de interesses, lobbies, sindicatos, etc.). Essas demandas são designadas como inputs; 2. No segundo, as demandas e apoios são agregados e organizados pelas instâncias representativas e transpostas ao governo; 3. Ao chegarem no governo são ordenadas em prioridades e traduzidas em políticas concretas (outputs), levando a resposta governamental a impactos concretos (outcomes). Dependendo de sua eficácia, as políticas públicas podem induzir um novo ciclo de demandas ou uma terminação da política. Por fim, a sucessiva reprodução dos ciclos do sistema político fortalece a eficácia política, crença no sistema, crescente cooperação e maior funcionalidade. Quando o ciclo politico corresponde às demandas sociais o regime é considerado funcional, denominando-se disfuncional diante dessa não correlação (CHILCOTE, 1981).

O institucionalismo teve sua inspiração na ciência política europeia, cujo tradutor mais eloquente foi o holandês Arend Lijphart (1968; 1969). Para Lijphart (1999) o desempenho da democracia (produção de políticas públicas efetivas) depende de dois fatores: o sistema político e a distribuição interna de autoridade entre o governo central e os governos subnacionais. O sistema político comporta quatro partes: 1 . Sistema eleitoral, 2. Sistema partidário 3. Relação entre executivo e legislativo, e 4. Natureza dos grupos de interesses. As quatro variáveis formam dois tipos ideais de democracias modernas: majoritária (Westminster do Reino Unido) e consensual (Suíça). O primeiro é distrital, bipartidário, centrado no executivo e com grupos de interesses mutáveis (lobbies). No segundo, existe a escoIha proporcional, multipartidária, equilibrando-se entre executivo e legislativo, detendo-se numa representação corporativa. Para os institucionalistas a efetividade das políticas públicas é maior no segundo, dado o fato que o grau da racionalização administrativa corresponderia a elevada representatividade do sistema eleitoral e partidário (LIJPHART, 1999).

Paralelamente às três abordagens das ciências políticas, economistas neoclássicos de Chicago entraram na arena, originando a teoria da escolha pública, uma aplicação dos princípios da economia neoclássica à análise política (EMMETT, 2010). A espinha dorsal deste pensamento é o conceito da racionalidade global (ou instrumental), a noção de que o homo economicus engloba todas as interações humanas, sejam econômicas, políticas ou culturais. A racionalidade implica num cálculo de custo beneficio que obedece a três premissas: 1 . a disponibilidade de plena informação para todos os atores, 2. o Estabelecimento de prioridades entre duas ou mais opções e 3 . o ordenamento das opções de acordo com o princípio transitório (Se $A>B$ e $B>C$ então $A>C$ ). Uma das referências da economia neoclássica é o "ótimo de Pareto" (conhecida popularmente por soma zero), situação onde o 
ganho de um ator equivale a perda do outro. Esta interação somente é viável num mercado competitivo em torno de recursos finitos. Para os economistas de Chicago, tanto os atores públicos como privados demonstram uma escolha racional utilitária (KASPER, 2002). Neste sentido, os políticos e as burocracias pública não são atores neutros nas disputas pela distribuição de valores na sociedade, mas são candidatos ao prêmio de apropriação privada (DOWNS, 1957). James Buchanan, um dos representantes desta linha, tachou a tese como "politics without innocence".

Essas linhas originais se ramificaram no final das décadas de 1950 e 1960. O racionalismo teve sua extensão no incrementalismo ${ }^{4}$ (muddling through) (LINDBLOM, 1959), o sistema do pluralismo ${ }^{5}$ (ABU-ELHAJ, 2014) no elitismo ${ }^{6}$, o institucionalismo no neo-institucionalismo (histórico, sociológico e racional) (HALL e TAYLOR, 2003) e a economia neoclássica na Escolha Pública. Nestas ramificações surgem as fraturas no consenso das três primeiras. Fraturas cau-

\footnotetext{
${ }^{4}$ Uma teoria realista da administração publica. Lindblom (1959) crítica o racionalismo de Lasswell, argumentando que a administração publica jamais dispunha de informações suficientes ou tempo hábil para estabelecer qual opção técnica seria a mais eficiente. As opções escolhidas são aquelas negociadas com os grupos de interesses. O que predomina concretamente é a legitimidade política e não a optimização técnica.

${ }^{5}$ Para os pluralistas, apesar das desigualdades econômicas, sociais e culturais, a igualdade política consegue equilibrar a disparidade de poderes. Esse fato é possível na medida que a pluralização dos recursos de poder econômico, político e cultural não se encontrariam sob o comando de uma única classe.

${ }^{6}$ Uma tese que segue a visão weberiana sobre a existência de uma nova a elite do poder no capitalismo moderno composta por detetores de cargos de autoridade nas grandes organizações administrativas publicas e privadas. Recursos do poder tais como acesso a poder financeiro, educacional, profissional, criam pesos políticos desiguais que influenciam as políticas publicas.
}

sadas por intervalos de lutas sociais e civis que questionaram a eficácia política da democracia representativa e a neutralidade das escolhas técnicas da administração pública racional-legal. Destas fraturas políticas surge a visão neo-pluralista na academia, uma fusão entre os dois rivais históricos, o pluralismo e o elitismo (DAHL, 1983; 2003). A dúvida dos neo-pluralistas era se a democracia pluralista (poliarquia) e suas instituições representativas se sustentavam como arenas neutras de arbitragem entre grupos de interesses. Concluíram que existe uma crescente assimetria de influencia nos três níveis das políticas públicas: macro (agenda), meso (formulação) e micro (implementação) (LINDBLOM ,1977 e 2001; e JANOSKI, ALFORD, HICKS e SCHWATRZ, 2005).

Paralelamente, a "Escolha Publica"7, a linha aplicada da economia neoclássica, alcança uma posição hegemônica na academia, emplacando, entre meados da década de 1970 e ano 2001, dezesseis prêmios Nobel de economia. A sua hegemonia acadêmica foi completada pela sua influência política no governo Reagan, quando William Niskanen assumiu a assessoria econômica da Casa Branca. A sua principal obra (1971) havia identificado a administração pública como um ator racional permanentemente agindo para expandir os gastos públicos como meio de ganhos pecuniários. Niskanen, na Casa Branca, minimizou as etapas de avaliação jurídicas e administrativas das fusões e aquisições entre grandes grupos empresariais, induzindo uma concentração econômica jamais vista desde a Grande depressão (HOVENKAMP, 1985). A obra de

\footnotetext{
${ }^{7}$ Estudos da ação coletiva de agentes políticos, tanto partidários como administrativos, como atores racionais atuando num ambiente de plena informação para maximizar seus benefícios.
} 
George Stigler, prêmio Nobel de 1982, tornou-se a justificativa acadêmica a favor da política de desregulação industrial e financeira (STIGLER, 1988). A influência da EscoIha Pública não se limitou aos países desenvolvidos. A frente do comando da política econômica dos governos conservadores, propagou-se nos organismos de desenvolvimento internacional. Por volta dos meados da década de 1990 havia surgido um consenso mundial em torno das privatizações, abertura comercial e redefinição dos direitos sociais.

Enquanto a Escolha Pública consagrava o mercado como a instância de eficiência na oferta de bens públicos, do neo-pluralismo ressurgiram temas clássicos sobre a natureza do poder político e sua adequação à sociedade humana: natureza do político, a definição da racionalidade, significados do público, formas de deliberações, policentrismo, agonismo etc. Quatro linhas distintas da democracia participativa se colocaram como alternativas à decadente democracia representativa: a linha da teoria política iniciada pela intervenção pioneira de Carole Pateman (1970 e 1985) sobre a pedagogia e cultura democrática; a linha sociológica de Jurgen Habermas (1974, 1983, 1987 e 1989) sobre as mutações da esfera pública e o papel da ação comunicativa na sua recuperação; a teoria econômica do policentrismo e autogestão de Elinor Ostrom (1990) e o pluralismo agonístico de Chantal Mouffe (1992 e 2013), uma síntese da vida activa de Hanna Arendt com a hegemonia de António Gramsci.

Deste renascimento de temas da democracias participativa e sobre natureza da política, quatro questões voltam a tona, questões originadas desde o nascedouro da disciplina. Estas questões se tornaram o centro de investigação do Plano Plurianual do governo municipal do Macapá.

1. Racionalismo e institucionalismo: Que modelos da administração pública demonstram mais eficácia na elaboração e implementação das políticas publicas? Modelos participativos, gerenciais ou empresariais? Que sistema politico é mais eficaz na agregação de interesses e desencadeamento de política públicas? majoritário ou consensual?

2. Sistema e pluralismo: Como os grupos de interesses se mobilizam, agregam recursos do poder e agem nas instâncias governamentais (o dilema da ação coletiva)? Quais são os resultados e as consequências (ganhadores e perdedores) quando os grupos de interesse atuam na macro política (ordenamento da agenda de prioridades), meso política (desenho e formulação de políticas públicas) ou micro política (implementação e avaliação)?

3. Economia neoclássica e Escolha Pública: A racionalidade econômica da teoria neoclássica se configura como um padrão global de intervenção dos agentes coletivos nas esferas política, cultura e social? A equidade e justiça social é um discurso éticonormativo ou tem fundamentos racionais na política moderna? A burocracia demonstra a mesma racionalidade econômica como os agentes privados na expansão dos seus ganhos materiais? A regulação governamental é um instrumento de distribuição equitativa de bens públicos, ou distorção de mercados?

4. Democracia participativa, deliberativa e radical: Como induzir uma cultura democrática nos espaços privados e comunitários na perspectiva de Pateman: educação política, escolas, formação partidária, campanhas midiáticas etc? A esfera pública é uma 
forma de organização restrita às elites letradas ou pode se ampliar para se tornar um padrão global de organização de interesses? É viável a recuperação da esfera pública e suas formas de comunicação na sociedade de massa lembrando Habermas? Como estabelecer previsibilidade e confiança entre os atores coletivos para tornar a autogestão uma realidade objetiva recordando Ostrom? O consenso político é uma mera ilusão? Somente com as lutas sociais e a contestação é que a sociedade resolveria seus impasses não esquecendo Mouffe? A hegemonia de Gramsci é fato reconciliável com a vida activa de Hannah Arendt?

\section{O CAMINHO PERCORRIDO}

Considerando o caráter qualitativo do estudo, as preocupações com a configuração dos componentes que integraram o desenho metodológico estiveram voltadas para proceder uma adequada concatenação entre as perspectivas da pesquisa, seus eixos teóricos e as abordagens metodológicas usadas para coleta, análise e interpretação dos dados. Cada perspectiva de estudo da gestão participava de Macapá, demandou esforços diferenciados para o estabelecimento do alinhamento entre os elementos teóricos e empíricos circunscritos a cada conjunto de questões norteadoras.

$\mathrm{Na}$ perspectiva histórica e da política local, o objetivo da pesquisa se concentrou em evidenciar elementos de caráter contextual que buscaram resgatar, desde sua origem até a contemporaneidade, fatos, trajetórias e conexões de caráter histórico, social e político que estabelecem contornos sobre o processo de configuração da regionalidade que caracteriza Macapá como Município. Nessa perspectiva, a obtenção de documen- tos históricos, somada à pesquisa bibliográfica, realização de entrevistas com pesquisadores locais e resgate de informações nos registros do Tribunal Superior Eleitoral, compuseram os principais métodos utilizados para a coleta de dados. O tratamento das informações se adequou à natureza de cada conjunto de dados, perpassando pela análise documental, análise de conteúdo e utilização de técnicas de análise descritiva de dados quantitativos.

Na perspectiva normativa e institucional, a atenção se voltou para identificar as características das dinâmicas induzidas pelo governo de Macapá na implantação da proposta de um novo modelo de gestão participativa nos anos de 2013 a 2016. Nessa perspectiva, a obtenção de documentos oficiais oriundos da Prefeitura Municipal e da Câmara de Vereadores e a realização de entrevistas episódicas com membros da administração pública municipal foram os principais meios usados para coleta de dados relacionados à maneira pela qual a participação social tem sido abordada na elaboração do planejamento público municipal e de que modo o governo que assumiu a administração de Macapá, em 2013, elaborou o planejamento plurianual e configurou a gestão da participação durante os quatro anos de mandato. O processamento das informações geradas foi realizado através da aplicação de técnicas de análise documental, e de análise de conteúdo, com o propósito de resgatar os elementos vinculados aos processos de gestão da participação contidos nas peças de planejamento municipal desde a criação do estado do Amapá e os elementos que distinguiram o desenho participativo adotado pelo governo municipal que exerceu o mandato no período compreendido no recorte deste 
estudo.

Na perspectiva dos atores sociais, a pesquisa buscou elucidar avanços, apropriações, conflitos, dificuldades e desafios percebidos no desenho institucional de gestão participativa implementado pela equipe de governo. Assim, a entrevista com representantes da prefeitura municipal, vereadores e representantes da sociedade que participaram do processo de elaboração e execução do planejamento plurianual do município foi a principal técnica de coleta de dados, utilizando-se a análise de conteúdo das entrevistas como procedimento metodológico de processamento e sistematização das informações geradas.

A pesquisa foi realizada entre junho de 2013 a setembro de 2016, perfazendo uma etapa inicial de sondagem preliminar até janeiro de 2015, com o propósito de mapear os principais atores sociais representativos e canais de acesso a informações, obtendo-se, em março do mesmo ano, anuência e autorização do Prefeito e do Presidente da Câmara Municipal de Macapá para proceder a observações, entrevistas e análise de documentos oficiais. Enquanto a obtenção de documentos oficiais se estendeu de fevereiro de 2015 até setembro de 2016, a abordagem de campo voltada para a realização das entrevistas foi efetuada de abril de 2015 a junho de 2016, envolvendo diálogos com onze pesquisadores locais, treze representantes da prefeitura municipal, dez vereadores e vinte e dois membros da sociedade (membros do Conselho Popular do Congresso do Povo) que estiveram envolvidos nos processos de elaboração e execução do planejamento municipal. Para seleção da amostra dos sujeitos a serem entrevistados na pesquisa foi levado em consideração as pessoas, as situações e os lugares que estiveram vinculados às dinâmicas de gestão participativas impulsionadas pela prefeitura, de tal monta que o conjunto selecionado de modo intencional fosse representativo para o estudo que estava sendo desenvolvido.

Ainda na dimensão empírica do estudo, durante outubro de 2014 e maio de 2016, foram realizadas vinte e nove observações catalogadas com anotações descritivas e reflexivas em cadernetas de campo, nelas constando: uma visita de observação em uma reunião com moradores durante a execução de serviço de asfaltamento em um loteamento do município; dez visitas de campo em uma ação integrada da prefeitura realizada em um dos bairros da zona norte da cidade; acompanhamento, em quatorze reuniões, de uma das equipes de gestão integrada da prefeitura; acompanhamento, em duas reuniões, de membros do Conselho Popular formado por representantes da sociedade; acompanhamento de uma ação integrada, durante quatro dias, em um dos distritos do Município de Macapá, e o acompanhamento do 3ㅇ Congresso do Povo realizado em dois dias de atividade na sede do município. Esses esforços de observação foram utilizados como elementos de amparo contextual na aproximação frente à realidade durante o processo de tratamento e sistematização dos dados obtidos na pesquisa.

Por mais que o desenho de pesquisa adotado apresentasse a possibilidade de agrupar enunciados que elucidassem elementos vinculados à interlocução entre integrantes da sociedade macapaense e o poder público, também apresentou algumas demarcações a serem consideradas quando se referem aos limites da trajetória percorrida. Nesse sentido, o recorte histórico não se 
propôs a perpassar fatos e acontecimentos ligados às características das disputas políticas e partidárias do cotidiano macapaense entre as elites locais, nos períodos pré e pós-estadualização do Amapá. A análise da elite política local também foi delimitada. Nesse caso, o recorte conteve-se apenas ao campo político eleitoral lastreado nos dados do Tribunal Superior Eleitoral. No que se refere ao recorte documental, foram considerados todos os documentos aos quais 0 acesso foi permitido, sendo apenas dois conjuntos documentos relevantes não analisados dada a dificuldade de localizá-los nos arquivos públicos (as peças de planejamento do Município de Macapá para os quadriênios de 1990 até 1993 e de 1994 até 1997). Por fim, no que diz respeito ao tratamento dos relatos contidos nas entrevistas, foi adotada a análise de conteúdo como abordagem frente às percepções explicitamente declaradas, não incorporando, sob o recorte analítico, a identificação e confronto de discursos implícitos subjacentes às narrativas dos atores que assumiram o papel de sujeitos da pesquisa.

\section{ENUNCIADOS}

A proposta de gestão ampliada do Município de Macapá, nos anos de 2013 a 2016, se apresentou como uma experiência de implantação de um desenho institucional participativo de condução política da coisa pública em um cenário caracterizado pela confluência de três elementos históricocontextuais. O primeiro, impulsionado pela Constituição de 1988 , diz respeito ao próprio processo de (trans)formação local que possibilitou, o surgimento de Macapá no cenário nacional como um município autônomo na qualidade de capital de uma nova
Unidade Federativa da União (estado do Amapá). Esse processo marcou o início de uma mudança nas estruturas de poder local.

O segundo elemento refere-se ao ideário participativo no contexto nacional, através das primeiras experiências de gestão participativa dos orçamentos municipais (a partir do final da década de 1980) e dos variados desenhos institucionais de participação implementados nas esferas nacional, estaduais e municipais a partir de 2003. Essa difusão tem estimulado uma parcela crescente de governos municipais a implementarem modelos de gestão participativa na condução da política local, promovendo consultas e compartilhando parte do poder decisório com representantes da sociedade.

$O$ terceiro elemento refere-se à ascensão de um novo grupo político na liderança da Prefeitura Municipal de Macapá, com a proposta de implementar um modelo de gestão inspirado nas experiências de participação social realizadas em outros municípios brasileiros e promover mudanças na cultura de gestão política da administração pública local.

Os esforços correspondentes a cada etapa do ciclo de pesquisa que integraram o presente estudo buscaram empreender um olhar que possibilitasse a identificação de relevos constantes na trajetória que caracteriza a formação socioeconômica e política da sociedade macapaense e na incorporação das dinâmicas participativas nos processos de gestão municipal. Ao final desta trajetória, as sínteses das reflexões obtidas foram agrupadas em enunciações que assumem o papel de afirmativas (teses) que também vão ao encontro das principais questões norteadores deste estudo.

Enunciado 1 - "Além do crescimento $e$ 
desenvolvimento socioeconômico e políticoterritorial do estado do Amapá serem considerados tardios sobre a perspectiva fronteiriça e urbanística, a emancipação de Macapá como capital de uma unidade territorial autônoma também é tardia sob o aspecto político-social, devendo-se entender que a conotação 'Macapá Tardia', longe de assumir uma perspectiva etnocêntrica, representa a condição de uma contemporaneidade caracterizada por um processo secular de formação de uma cultura amazônida possuidora de traços singulares e de tecido social que expressa características próprias de autogestão com uma elite política local ativa".

Enunciado 2 - "Por mais que seja uma localidade secular, com uma história políticosocial profundamente associada à garantia estratégica da segurança nacional e ocupação territorial do Norte da foz do Rio Amazonas, o crescimento populacional e urbano é recente, com participação expressiva de migrantes, especialmente oriundos do Pará, que integram, em proporções similares, a composição demográfica, tanto da sociedade quanto da elite política local. Estima-se a ocorrência de outra onda migratória para a região, provavelmente impulsionada pelos efeitos da regulamentação da Zona Franca Verde de Macapá e Santana e de novos empreendimentos associados ao agronegócio $e$ provenientes da obtenção de títulos definitivos de terras no Estado".

Enunciado 3 - "Depois da criação do estado do Amapá, em 1988, até o ano de 2014, aproximadamente 150 lideranças locais têm se apresentado como integrantes de uma elite política possuidora de representatividade para exercer cargos eletivos nas esferas executiva e legislativa. Mesmo havendo a existência de sete prováveis gru- pos familiares expressivos, que têm disputado e ocupado esses postos na estrutura de poder institucional do município de Macapá e do estado do Amapá, ainda não se pode afirmar a existência de oligarquias familiares tradicionais consolidadas".

Enunciado 4 - "Os partidos políticos que atuaram no campo político eleitoral do estado do Amapá (incluindo o Município de Macapá) como principais aglutinadores de candidatos foram o PDT, PSB, PSDB e PT. Já, no que se refere à quantidade de vitórias nos pleitos, observa-se que os partidos que tiveram maior quantidade de candidatos eleitos foram o PDT, PMDB e PSB. Entretanto, estima-se que se futuramente ocorrer um processo de saída de apenas duas lideranças partidárias específicas no PSB haverá forte impacto nos resultados que historicamente o partido vem apresentando".

Enunciado 5 - "Existe uma reduzida integração entre os blocos de lideranças que vêm, historicamente, disputando e ocupando postos na estrutura de poder entre o Município de Macapá e o estado do Amapá. Esse fato recorrente é identificado quando se percebe que as intencionalidades declaradas pelas gestões municipal e estadual denotam convergências de propósito na direção da promoção do desenvolvimento $e$ bem-estar social, mas se operacionalizam de forma contraditória quando necessitam atuar de forma integrada. Esse fato sinaliza que nas principais clivagens políticas têm envolvido disputas de posicionamento territorial entre grupos familiares, grupos de interesses específicos e de lideranças locais isoladas em detrimento de disputas que envolvam a discussão sobre estratégias e ações políticas integradas que estejam fundamentadas em ideologias programáticas".

Sob a ótica dos enunciados contextuais, 
vale destacar que por mais que o crescimento/desenvolvimento socioeconômico e político-territorial local seja considerado tardio por Porto (2014), Tostes e Tavares (2014) e Tostes, Souza e Ferreira (2015), a emancipação de Macapá, na condição de capital, também é tardia, ao se considerar que essa emancipação já era defendida por Candido Mendes em 1853, solicitada por lideranças locais em 1870 e 1920 e defendida por parlamentares amapaeneses no Congresso Nacional em 1949, 1967 e 1987 (DE ALMEIDA, 1868, p. 32-35; 1873, p.XIXXIV; REIS, 1949, p.178-180; NUNES, 1949, p. 2631-2632; 1967, p. 217-219; BARCELLOS, 1987, p.3582-3583).

Circunscrito ao campo eleitoral, um montante de 2.445 pessoas se envolveram no cenário político amapaense através de inscrições nos pleitos de 1994 até 2016, defendendo as mais variadas propostas ideológico-partidárias e disputando postos na estrutura do Estado para prefeito de Macapá, vereador, governador, deputado estadual, deputado federal e senador. Ao proceder análise visando extrair a relação de candidatos que obtiveram vitórias eleitorais nos respectivos pleitos, foram identificadas 154 pessoas, consideradas, neste estudo, integrantes da elite representativa do campo político local por possuírem força de mobilização capaz de torná-las mandatárias e 38 pessoas que obtiveram de três a seis vitórias eleitorais, envolvendo tentativas que variaram de três até oito inscrições para os postos do executivo e legislativo, sendo consideradas neste estudo lideranças expressivas no campo da política eleitoral local

Quando se analisa o vínculo entre a quantidade de tentativas realizadas pelos candidatos para a ocupação de postos com o número de vitórias eleitorais obtidas em todo o horizonte estudado, percebe-se a existência de uma configuração de disputas eleitorais composta de lideranças locais fortes que se concentram principalmente em estabelecer bases eleitorais com territorialidades situadas com preponderância na esfera municipal e lideranças que estabelecem bases eleitorais mais ampliadas com foco predominante nos postos disponibilizados nas eleições estaduais e federais.

A listagem reputacional, obtida através de um processo de saturação em primeira rodada de entrevistas, dos prováveis blocos familiares que integram a dinâmica de formação da elite política local, englobou 15 sobrenomes. Através da combinação de inscrições eleitorais, vitórias eleitorais e Grau de Afinidade Familiar foram identificados sete grupos de antropônimos que denotaram apresentar considerável densidade nos valores obtidos. Os sobrenomes Góes, Capiberibe, Alcolumbre, Borges, Favacho, Amanajás e Gurgel surgem no período analisado como àqueles que mais se destacam como unidades coletivas ${ }^{8}$. Vale esclarecer que a identificação desses integrantes da elite política local limitou-se à análise das relações entre os antropônimos (sobrenomes) dos candidatos nos processos eleitorais sem o direcionamento de esforços visando descortinar as efetivas relações

\footnotetext{
${ }^{8}$ Além dos sobrenomes Nunes, Barcellos, Ramos, Picanço, Nery, Guerra, Abdon, e Colares que foram identificados na primeira rodada de entrevistas, uma listagem reputacional complementar para estudos futuros foi obtida através de articulistas locais que participaram de uma segunda rodada de entrevistas com o propósito de efetuar o estabelecimento do Grau de Afinidade Familiar. Os seguintes antropônimos compuseram esta respectiva listagem: Távora; Pinheiro; Ferreira; Souza; Rocha; Juarez; Quintas; Salomão; Coelho; Houat; Harb; Zagury; Trindade; Duarte e Garcia.
} 
de parentesco, consanguíneo ou matrimonial, entre as pessoas que ocupam posições na estrutura de poder em Macapá, envolvendo, por exemplo: a ocupação de cargos de confiança no executivo e legislativo; de cargos efetivos e contratados; de cargos no judiciário, dentre outros.

Entretanto, essa configuração permite estabelecer uma representação de campo político composto de quatro grandes blocos de lideranças locais que disputam entre si, e dentro de cada bloco, posicionamentos no campo eleitoral. O primeiro é composto pelos expressivos grupos familiares vinculados partidariamente com as mais variadas tendências ideológicas, como por exemplo Góes (PDT), Capiberibe (PSB), Alcolumbre (DEM), Borges, (PMDB), Favacho (PMDB), Gurgel (vínculo partidário difuso) e Amanajás (vínculo partidário difuso). O segundo bloco é composto pelos grupos familiares pequenos, com diversos padrões de vínculo ideológico partidário que se encontram em processo de entrada/ascensão no campo ou declínio/saída do cenário político eleitoral, por exemplo, Abdon e Barcellos. O terceiro bloco de lideranças é composto por grupos de interesses específicos vinculados a partidos isolados ou a coligações partidárias (explícitas ou não), que disputam posicionamentos na estrutura do Estado, por exemplo as bancadas socialistas formadas por integrantes de partidos de esquerda. O quarto bloco é composto por lideranças locais isoladas que se candidatam nas disputas eleitorais, revelando pautas motivacionais diversas e vinculações partidárias difusas.

Com base no comportamento constatado nas trajetórias dos diversos atores envolvidos nesse campo, convém dizer que essa representação é uma estrutura dinâ- mica, na qual novas lideranças, famílias e grupos de interesse entram, se deslocam e saem do campo eleitoral impulsionados por fatores diversos, sendo esse um ponto de pauta sugerido para agendas de pesquisas futuras sobre Macapá.

Os enunciados sobre o processo de gestão participativa implementado no período de 2013 a 2016 são os seguintes:

Enunciado 6 - "A intencionalidade declarada dos governos municipais em promover a participação social na gestão de Macapá integrou os processos de planejamento desde os primeiros governos municipais eleitos. Entretanto, essa intencionalidade declarada só se mostra traduzida em programas governamentais, com dotação orçamentária para a gestão institucionalizada da participação nos Planos Plurianuais a partir de 2002 com a criação do Programa Mobilização Social".

Enunciado 7 - "O primeiro processo registrado de elaboração participativa de um Plano Plurianual no Município de Macapá foi executado no ano de 2009, sendo caracterizado por uma experiência eminentemente de caráter consultivo, incorporando programas de gestão da participação social com previsão de dotações orçamentárias. Nessa experiência, a participação centrouse na representatividade de entidades da sociedade civil organizada, havendo um número reduzido de participantes e sem a criação de mecanismos de controle social para a sua implementação".

Enunciado 8 - "O primeiro processo participativo de elaboração do planejamento plurianual do Município de Macapá, em caráter deliberativo, foi realizado em 2013, caracterizando-se como sendo a experiência de elaboração que agregou maior número de pessoas do município, instituiu maior 
número de programas de gestão da participação e alocou maior aporte orçamentário nos programas dessa natureza. Essa experiência também foi marcada pela criação de mecanismos de gestão e fiscalização social para a implementação do respectivo Plano, através da criação de Instituições Participativas, entre as quais o Congresso do Povo (composto por um Conselho Diretor) e Comissões Populares de Fiscalização".

Enunciado 9 - "A proposta de modelo de gestão participativa implantada no Município de Macapá, durante o período de 2013 até 2016, caracterizada por um desenho institucional que propunha a integração de membros da sociedade na elaboração e execução do Plano Plurianual do município, através da criação do Congresso do Povo, $e$, posteriormente, do conselho gestor, apresentou evidências que apontaram avanços e empoderamentos".

Enunciado 9.1 - "A aproximação da administração pública municipal com a sociedade foi o avanço mais perceptível do modelo de gestão adotado, principalmente nos primeiros anos de mandato, havendo aprendizado, tanto de membros da sociedade quanto de integrantes do governo municipal".

Enunciado 9.2 - "Os principais empoderamentos na etapa de elaboração do planejamento municipal foram relacionados à capacidade assumida de mediação e gestão de conflitos entre os próprios indivíduos da sociedade, nos espaços abertos para deliberações públicas e do uso desses espaços pelos respectivos membros da sociedade, para proporem e deliberarem sobre alternativas de soluções para os problemas da cidade. Após a etapa de planejamento, a reivindicação, por parte dos representantes da sociedade eleitos pelo Congresso do Povo, para ter acesso aos órgãos da prefeitura foi o traço de apropriação mais percebido".

Enunciado 10 - "Por mais que o processo de gestão participativa instituído em terras Tucujús tenha gerado avanços e apropriações, ele também foi acompanhado por conflitos, limites e dificuldades".

Enunciado 10.1 - "A busca para assegurar o agendamento e execução de serviços para suas localidades sobressaiu como interesse subjacente dos principais conflitos entre os próprios membros da sociedade, expressos, geralmente, pela irredutibilidade na defesa de propostas durante a etapa de elaboração do Plano Plurianual de Macapá e na disputa pela priorização da execução de obras e serviços durante a sua implementação".

Enunciado 10.2 - "Os principais conflitos dos representantes da sociedade com os membros da prefeitura municipal de Macapá estiveram relacionados ao estabelecimento da agenda executiva de prestação de serviços públicos da prefeitura, sendo identificados através resistência de indivíduos da sociedade em aceitarem a inviabilidade técnica de algumas reivindicações e através das disputas entre delegados, gestores $e$ técnicos pelo estabelecimento da ordem de execução de obras e serviços. Outro conflito percebido entre membros do governo e representantes da sociedade gravitou em torno da resistência de alguns secretários $e$ responsáveis de órgãos da prefeitura em atender delegados e conselheiros, gerando insatisfações e afastamentos".

Enunciado 10.3 - "No que se refere aos limites e dificuldades relacionados à proposta de gestão ampliada adotada pela Prefeitura de Macapá nos anos de 2013 a 2016, se destacam: 1) a pouca experiência e sobrecarga de trabalho da equipe de governo 
no início do mandato; 2) o pouco envolvimento de alguns gestores com os representantes da sociedade e resistência em aderirem ao modelo e gestão participativa; 3) a não realização de reforma administrativa alinhada às diretrizes da nova política de gestão; 4) o pouco conhecimento dos representantes da sociedade sobre os processos de planejamento público municipal; 5) a descrença da sociedade com a classe política; 6) a dificuldade de locomoção dos delegados do Congresso do Povo e os problemas de infraestrutura e logística relacionados ao seu funcionamento; 7) a falta de recursos financeiros da prefeitura para execução de várias de suas ações programadas; 8) a dificuldade de acesso dos delegados aos órgãos da prefeitura; e 9) a dificuldade de efetivação da abordagem participativa com a mesma magnitude nas etapas de execução, controle e avaliação do Plano Plurianual".

Enunciado 11- "Cinco características distinguem a experiência macapaense de implementação do modelo de gestão participativa realizada no período de 2013 a 2016: 1) no primeiro ano de mandato houve significativa mobilização de capital social e participação da sociedade no estabelecimento de parte da agenda de planejamento do governo através do Congresso do Povo; 2) durante todo o processo houve reduzida tensão entre vereadores e delegados do Congresso do Povo, principalmente pelo fato de os dois conjuntos de atores não estarem em uma mesma arena de conflitos de interesses relacionados ao planejamento orçamentário do município; 3) no decorrer do mandato percebeu-se uma gradual redução dos canais de diálogo entre a prefeitura municipal e os delegados do Congresso do Povo; 4) a partir da segunda metade do mandato, o governo alterou a abordagem dada aos processos de relacionamento com a sociedade, implementando uma estratégia mais pragmática de gerenciamento integrado de priorização e negociação de demandas; e 5) ocorreu, no decorrer da gestão, um perceptível enfraquecimento do Congresso do Povo como instituição participativa".

No horizonte temporal resgatado, foram obtidas informações relacionadas aos seis últimos planos elaborados no município, cobrindo uma faixa de 23 anos de pretensões declaras pelos respectivos prefeitos em seus exercícios. No corpo da mensagem em que o prefeito Papaléo Paes (PSDB) encaminhou o Plano Plurianual do quadriênio 1994-1997 para a Câmara de Vereadores, são listadas oito diretrizes de ação governamental, e, dentre elas, a participação popular já se apresentava como intencionalidade declarada. A vontade de abrir diálogo direto com os cidadãos também é mencionada na mensagem que o seu sucessor, Annibal Barcelos (PFL), em uma de suas estratégias estabelecidas no arcabouço do plano. Entretanto, além de não haver detalhamento da metodologia usada e registro de participação da sociedade na elaboração do Plano, a gestão da participação pretendida na respectiva estratégia não estava traduzida em nenhum dos 26 Programas contidos no PPA ${ }^{3}$.

O outro gestor na linha sucessória foi João Henrique Rodrigues Pimentel que assumiu a Prefeitura Municipal de Macapá por duas administrações consecutivas, eleito na primeira pelo PSB e na segunda pelo PT. Em sua mensagem de encaminhamento do Plano Plurianual do quadriênio 2002-2005 apresentou breve menção a um amplo processo participativo, sem haver, no arcabouço do PPA, registro de detalhamento da 
metodologia utilizada, nem registros de participação direta da sociedade na elaboração respectivo plano. Entretanto, a intencionalidade da gestão da participação social é identificada em uma das diretrizes de governo (Prefeito e Povo Decidindo Juntos) e em uma das dimensões estratégicas (Promoção da Cidadania e a Inclusão Social), sendo traduzida em um dos 29 Programas contidos no Plano (Programa Mobilização Social). Em seu segundo mandato, o prefeito passou à Câmara uma nova mensagem ao encaminhar o PPA do quadriênio 20062009, a qual menciona apenas que a participação popular na gestão da cidade deve ser enfatizada através da utilização de instrumentos, entre os quais órgãos colegiados de política urbana, debates, audiências e consultas públicas. Na estrutura do plano houve um detalhamento superficial da metodologia utilizada, informando que o PPA foi baseado no Plano Diretor de Desenvolvimento Urbano e Ambiental de Macapá; no Plano Estratégico da equipe gestora de 2005 e nas informações advindas da II Conferência da Cidade realizada em Macapá. Entretanto, a intencionalidade da gestão da participação social é identificada semanticamente em um dos eixos estratégicos (Desenvolvimento Humano e da Cidadania) e novamente traduzida em um dos 36 Programas apresentados no respectivo Plano (Programa Mobilização Social).

O próximo prefeito a assumir a gestão municipal, Antônio Roberto Rodrigues Góes da Silva (PDT), enviou à Câmara Municipal, em 2009, mensagem de encaminhamento do PPA para o quadriênio 2010-2013, informando que o referido Plano levava em conta propostas e sugestões colhidas em um processo de participação popular através da realização de Audiências Públicas e
Fóruns Distritais, assumindo que os membros da sociedade civil possuíam condições de subsidiar os órgãos da prefeitura nos processos de identificação de demandas e seleção de políticas públicas. No arcabouço do Plano enviado aos vereadores houve o detalhamento da metodologia e da execução de quatro Audiências Públicas e de oito Fóruns Distritais, relatando a participação de 464 pessoas e 80 instituições nas audiências, e de 181 pessoas de 68 entidades/comunidades nos fóruns. A abordagem dada aos canais abertos de diálogo com a sociedade foi de caráter eminentemente consultivo, sem haver, na estrutura do plano, a criação de instrumentos participativos de gestão e de controle social para sua implementação. A intencionalidade da gestão da participação social é identificada no eixo estratégico Gestão Democrática, Inclusão Social e Cidadania e traduzida em três dos 50 Programas apresentados no respectivo Plano (1- Programa Mobilização Social; 2Programa Comunidade Forte e 3- Programa Espaço da Cidadania).

O último prefeito, na linha sucessória, a assumir a administração municipal, foi Clécio Luís Vilhena Vieira, eleito pelo PSol. Em sua mensagem de encaminhamento do Plano Plurianual do quadriênio 2014-2017 para a Câmara, o referido prefeito destacou a participação social como elemento central do processo de elaboração do plano, realizada através de uma metodologia denominada "Congresso do Povo", com o envolvimento de 700 representantes eleitos em Assembleias Populares que mobilizaram direta e indiretamente mais de 10 mil pessoas de várias idades e classes sociais dos diversos distritos, bairros e localidades do município. No corpo do Plano enviado aos vereadores houve apresentação da meto- 
dologia, com o detalhamento da execução das Assembleias Populares consultivas e da Plenária Final deliberativa. Foi relatada a participação direta de 6.996 pessoas eleitas nas 18 Assembleias Populares, as quais indicaram demandas locais e elegeram 700 representantes (denominados Delegados) para participarem dos Grupos de Trabalho e Plenária Final do Congresso do Povo com o objetivo de discutirem e deliberarem sobre as demandas que deveriam ser consideradas prioritárias no PPA.

Salienta-se que, no corpo do respectivo Plano Plurianual, a gestão da participação social foi identificada na primeira diretriz de ação governamental (O Povo no Comando), incorporada ao Eixo de Desenvolvimento Desconcentrado e traduzida em seis dos 58 Programas apresentados no respectivo Plano (1- Programa Mobilização Social; 2- Programa Olho Vivo no Dinheiro Público; 3Programa Macapá Gestão e Cidadania; 4Programa Ouvidoria-Canal aberto e participação da População; 5- Programa Povo no Comando e 6- Inclusão, Cultura e Cidadania - Viver Cultura).

Com amparo nessa retrospectiva, constata-se que a gestão institucionalizada da participação social no desenvolvimento das políticas públicas em Macapá tem sua intencionalidade traduzida no planejamento das ações governamentais desde 2002, com a criação do Programa Mobilização Social, e obteve contornos diferenciados a cada ciclo de gestão. Um fato que chama a atenção diz respeito ao significativo aumento do número de Programas Governamentais vinculados à gestão institucionalizada da participação social e o expressivo aumento do volume de recursos orçamentários disponibilizados para esses programas a partir de 2014.
Dentro de uma perspectiva comparativa entre os ciclos de planejamento, observouse uma significativa atenção dada para a participação social no último PPA, indicando coerência e alinhamento entre discurso declarado na mensagem do prefeito e alocação de valores orçamentários para execução de suas ações no início de seu mandato. Esse alinhamento é expresso no total de recursos destinados à gestão institucionalizada da participação e no quantitativo de recursos destinados ao Programa Povo no Comando. No primeiro caso, o preceito participativo como marca de governo foi refletido por um montante de recursos alocados equivalente a 6,4 vezes o valor de todos os PPAs anteriores somados. No segundo caso, a diretriz de governo denominada "Povo no Comando" foi refletida em um programa, de mesmo nome, cujos recursos equivaleram a 2,9 vezes o montante total alocado para o conjunto dos programas vinculados à gestão da participação no PPA anterior. Vale destacar que nessa análise levou-se em consideração apenas a intencionalidade declarada no início dos mandatos dos Prefeitos de Macapá, utilizando como critério os recursos alocados no Plano Plurianual em sua primeira versão. A análise da concretização dessas intencionalidades, refletidas na destinação e execução dos respectivos recursos, foge ao escopo deste estudo, sendo este assunto considerado importante pauta a ser incorporada em agenda de pesquisas futuras, à medida que ajustes orçamentários e financeiros são frequentemente realizados, alterando os montantes das dotações e valores empenhados, liquidados e pagos.

Após a elaboração do PPA em 2013, enquanto um vetor de participação institucional se configurava através da pressão de 
delegados na direção dos órgãos da prefeitura, outro vetor de mesma natureza, gradativamente, se fez presente na direção inversa, através da implementação das "Caravanas do Povo no Comando" (mutirões operacionais da prefeitura, integrados pela Secretaria Municipal para Assuntos Extraordinários-SEMAE, com o propósito de realizar ações e serviços em conformidade com as secretarias que estavam à frente das demandas mais requisitadas pela população que morava em áreas de risco ou periféricas).

Percebendo as dificuldades operacionais para gerir diretamente as demandas provenientes de todos os delegados eleitos no 10 Congresso do Povo em 2013, a prefeitura reconfigurou o desenho institucional do processo participativo na intenção de proporcionar aos respectivos delegados a possibilidade de autogestão e o estabelecimento de uma instância de interlocução com um número mais reduzido de delegados. Nesse contexto, a concepção do 20 Congresso do Povo se ancorou na apresentação do balanço das ações realizadas e na transformação do Congresso do Povo em um instrumento público de gestão e participação popular composto por um conselho na qualidade de órgão de direção. O Congresso, realizado em maio de 2014 , se desenvolveu com a participação de 533 pessoas em uma ambiência que envolveu a preocupação, por parte dos gestores, em apresentar as metas que foram cumpridas e, por parte dos delegados presentes, um conjunto de manifestações que aglutinou demonstrações de reconhecimento dos avanços obtidos, insatisfações frente à dificuldade de acesso às secretarias municipais e falta de recursos para custear as despesas dos delegados nas atividades de fiscalização, além das expectativas frente à configuração gerada com a instituição do novo Conselho.

De acordo com o seu Regimento Interno, o Conselho Popular do Congresso do PovoCONPOP foi composto por 41 membros, eleitos entre os delegados presentes no Congresso, e por 37 membros a serem indicados pela prefeitura. A coordenação foi definida como bipartite, com seis pessoas, sendo três delegados e três representantes da prefeitura, sob a coordenação geral da SEMAE, com competência de deliberar sobre os planos de investimento e de ação das atividades da prefeitura; de analisar, deliberar e coordenar os debates populares sobre o PPA e de analisar, opinar e coordenar os debates populares sobre a política tributária do município. Com essa reestruturação do desenho institucional, o Congresso do Povo assumiu nova configuração, visando direcionar a centralidade da gestão deliberativa para o CONPOP.

Os efeitos da crise fiscal que despontam em 2014 geraram impactos na gestão municipal, dificultando a execução de diversos projetos e a conclusão de obras e serviços programados. Embora o prefeito tivesse anunciado à Câmara, em sua mensagem de abertura do ano legislativo de 2014, que pretendia superar os desafios encontrados no primeiro ano de mandato e vivenciar um cenário de melhoria de investimentos, o que ocorreu, na prática, foi a implementação de medidas de mitigação frente à redução dos repasses constitucionais do Fundo de Participação dos Municípios. Essa situação foi exposta em sua mensagem na abertura do ano legislativo de 2015, anunciando que as novas medidas para enfrentar a crise seriam fundamentadas em uma política de austeridade fiscal e implantação de um plano de obras vinculadas à obtenção de trans- 
ferências voluntárias federais. Nesse período, as Caravanas do "Povo no Comando" vinham cada vez mais assumindo um papel relevante como instrumento utilizado pela prefeitura para a realização de pequenos serviços generalizados em várias localidades do município, com custo acessível e grau significativo de diálogo e negociação com os moradores e lideranças locais.

Percebendo a redução dos níveis de participação, o aumento da pressão social sobre a estrutura da prefeitura e os resultados obtidos pelas Caravanas do "Povo no Comando", a prefeitura voltou seus esforços para reconfigurar novamente o desenho institucional do processo participativo, na intenção de enfrentar os efeitos da crise fiscal sem perder a sua capacidade de prestar serviços públicos com o uso de canais de diálogo com a sociedade. Desta forma, a partir do ano de 2015, a concepção que caracterizava a marca central do governo ( $O$ Povo no Comando) foi redefinida, havendo uma alteração perceptível no vetor de relação que era desejado no início da gestão. Embora o preceito da participação ainda marcasse a lógica da relação entre prefeitura e sociedade, a direção e natureza desse fluxo sofreu inversão à medida que a prefeitura assumiu explicitamente a responsabilidade de definir as ações que seriam prioritárias frente à incapacidade de atender a todas as demandas. Essa transformação foi marcada pela implementação, em junho de 2015, de uma estratégia de gestão voltada para colocar a prefeitura mais próxima da população através da realização difusa de serviços em menor escala de recuperação e revitalização de espaços públicos, denominada "Prefeitura na sua Rua", cuja coordenação dos trabalhos relativos à sua operacionalização foi assumida pela Secretaria
Especial de Coordenação das Subprefeituras-SECSUB. Consequentemente, a lógica fundante da principal diretriz participativa de governo, a partir desse momento se pragmatizou assumidamente no atendimento também de demandas difusas para além das prioridades advindas dos fóruns deliberativos anteriormente instituídos.

Nesse contexto, sob a coordenação exclusiva da Prefeitura Municipal, a concepção e realização do 3을 Congresso do Povo, em novembro de 2015 com o credenciamento de 217 pessoas, se direcionou principalmente para a apresentação das prestações de contas das ações realizadas e reestruturação do CONPOP, através da recondução dos conselheiros que estavam "ativos" e substituição dos conselheiros que não estavam mais atuando. Com esse reordenamento, o desenho institucional da participação assumiu nova configuração, marcada pela mudança da lógica de relacionamento da prefeitura com a sociedade e por um dilema estrutural provocado pela coordenação e desenvolvimento das atividades do Congresso do Povo pela Prefeitura Municipal fora dos dispositivos estabelecidos pelo seu Regimento Interno.

No que se refere à participação, além dos aspectos quantificáveis advindos dos documentos que detalham a realização das atividades de elaboração participativa do Plano Plurianual do Município de Macapá em 2013, vários relatos possibilitaram atestar a objetivação da abertura de espaços públicos deliberativos para a definição de prioridades na agenda de planejamento municipal durante o primeiro ano de mandato do prefeito. Nesse aspecto, as principais convergências observadas estão relacionadas ao empoderamentos e aos avanços percebidos. Nesse sentido, a capacidade 
de deliberação dos delegados eleitos nas Assembleias Populares, nos Grupos de Trabalho e na Plenária Final do Congresso do Povo, em 2013, se apresentam como variáveis convergentes de destaque ao lado de outros empoderamentos como: 1) a capacidade adquirida dos delegados de usar os espaços abertos naquele ano para propor soluções à cidade; 2) o exercício do poder dos moradores e lideranças locais para além dos presidentes de associações; e 3) a autoimagem assumida por alguns delegados de "vereador do povo". Outros dois traços que também assumem caráter de variáveis denotadoras de mudança referem-se aos processos de implantação de um novo modelo diferenciado de elaboração do PPA e de aprendizado adquirido tanto por membros da sociedade quanto por integrantes da própria prefeitura.

Em todo o período analisado, a prefeitura municipal assumiu papel de protagonismo no processo de articulação e criação de ambientes compartilhados de deliberação, no entanto, houve, no primeiro ano de mandato, um elevado esforço de mobilização de capital social $^{9}$ com o propósito de

\footnotetext{
${ }^{9}$ Resgatando-se, no escopo deste estudo, os preceitos conceituais de Bourdieu (2010, p. 67), o capital social é entendido como "o conjunto de recursos atuais ou potenciais que estão ligados à posse de uma rede durável de relações mais ou menos institucionalizadas de interconhecimento ou de inter-reconhecimento", estando o seu volume relacionado à extensão da rede de relações e ao volume dos capitais dos integrantes que compõem a respectiva rede. $O$ capital social também pode ser abordado sob a perspectiva do fluxo, da distribuição, da fragmentação e da polarização, cuja conjugação com a participação social é entendida como elemento importante para o fortalecimento da democracia (FERRAREZI, 2003). No que se refere à dinâmica de mobilização do capital social, Abu-al-Haj (1999, p.109-111) aponta três processos políticos críticos vinculados à sua institucionalização. São eles: 1) Mobilização de recursos de poder (afinidade pessoal, adesão ideológica e participação dos
}

promover mudanças. Sob esse aspecto, o conjunto de recursos da organização coletiva mobilizado foi formado pelos grupos de gestores e técnicos da prefeitura, por colaboradores externos que já haviam vivenciado experiências similares em outros estados, e por grupos de moradores e lideranças locais. Os principais blocos de poder formados nesse período foram representados pelos integrantes do núcleo gestor do governo, delegados do Congresso do Povo e integrantes das primeiras Comissões Populares de Fiscalização. No primeiro ano de mandato, a institucionalização da autonomia adquirida ancorou-se na estrutura administrativa da prefeitura através da Secretaria Municipal de Planejamento-SEMPLA e SEMAE, sendo ampliada na esfera social através do Congresso do Povo em suas assembléias populares, grupos de trabalho, plenária final e, posteriormente, através das comissões populares de fiscalização .

O Congresso do Povo surgiu como marca e expressão representativa da proposta de gestão participativa implantada pelo governo municipal que assumiu a prefeitura de Macapá em 2013. Enquanto no primeiro ano de mandato o Congresso do Povo assumiu o papel de metodologia participativa para a elaboração do PPA (formando o corpo de 700 representantes sociais que atuariam como delegados na priorização de demandas e fiscalização das ações da prefeitura), no segundo ano, o Congresso do Povo foi transformado em instituição participativa gerida regimentalmente por um conselho. No final do terceiro ano de mandato, os delegados do Congresso do Povo

membros do grupo no direcionamento da ação coletiva); 2) Formação de blocos de poder (reunindo grupos sociais diversos); e 3) institucionalização do consenso político em ações e procedimentos administrativos. 
foram mobilizados para se reunirem com o propósito de participar mais uma vez da prestação de contas anual do governo e recompor o conselho gestor com novos membros. Já, no último ano do mandato, não houve mobilização dos delegados $\mathrm{e}$ conselheiros do Congresso do Povo para a realização das assembleias populares e plenária municipal para prestação de contas e deliberações.

O Congresso do Povo, como metodologia de elaboração do PPA, denotou ter sido um efetivo mecanismo de inserção social nas camadas deliberativas do estabelecimento das agendas de planejamento municipal. Mesmo não sendo estendido para as outras peças de planejamento orçamentário (Lei de Diretrizes Orçamentárias-LDO e Lei de Orçamento Anual-LOA), a abordagem participativa pareceu ter gerado efeitos positivos nas esferas do aprendizado e do empoderamento. Entretanto, a institucionalidade do Congresso do povo como instância deliberativa e fiscalizadora, por mais que tenha possibilitado a criação de um canal voltado a promover as interlocuções entre a estrutura administrativa da prefeitura e representantes das diversas localidades do município, não conseguiu ser operacionalizada em sua plenitude. Limites e dificuldades relacionados à infraestrutura e logística, associados à elevada dependência institucional do governo municipal como indutor da mobilização da sociedade, despontaram como fatores críticos desse processo de enfraquecimento. Outras variáveis que se mostraram convergentes dizem respeito: 1 ) aos limites da capacidade dos delegados e conselheiros em cumprir a agenda participativa; 2 ) às disputas de poder internas entre os próprios delegados/conselheiros; e 3) às dificuldades de acesso dos delegados $\mathrm{e}$ conselheiros aos órgãos da prefeitura, gerando conflitos relacionados à resistência de alguns integrantes da prefeitura em aderirem ao novo modelo de gestão.

$O$ processo de enfraquecimento do Congresso do Povo se apresenta como um dos sinais mais expressivos de diminuição da consistência da mobilização do capital social promovido pelo governo municipal na direção de instituir a proposta original de gestão participativa, à medida que a institucionalidade de uma autonomia inserida não foi consolidada, tornando-se ausente no último ano de governo, quando por falta de indução da prefeitura não foram realizadas as assembleias populares e plenária municipal do Congresso do Povo, em 2016.

\section{CONSIDERAÇÃO FINAL}

Por mais que não seja intenção do presente estudo avançar no domínio da pragmática, frente aos resultados gerados, julga-se propício tecer uma proposição fundamentada no pressuposto da mudança direcionada ao desenvolvimento e ao aperfeiçoamento da experiência vivenciada em Macapá. Dessa forma, partindo-se do desenho de gestão adotado pela Prefeitura Municipal de Macapá nos anos de 2013 a 2016, e das percepções sobre seu processo de implantação, depreende-se a necessidade de redução da centralidade do governo na gestão das Instituições Participativas e da efetiva ampliação do processo participativo para além das etapas iniciais de elaboração do PPA, LDO e LOA, visando superar as dificuldades encontradas no acompanhamento das ações de fiscalização e controle, e também no acesso dos representantes da sociedade aos vários setores da prefeitura.

Sob a perspectiva da produção do co- 
nhecimento e da sua difusão, algumas alternativas de desdobramentos deste estudo se apresentam como opções de continuidade do caminho que se acaba de percorrer. Na Dimensão da Institucionalidade, a criação de um grupo de trabalho que busque monitorar os processos e dinâmicas de gestão pública no estado do Amapá, e em seus municípios, surge como alternativa de plataforma local indutora de produção e difusão de conhecimentos sobre o tema incorporando as seguintes linhas de monitoramento entendidas como fundantes para a percepção das transformações locais: 1) Elites Políticas e Processos Eleitorais; 2) Gestão da Participação e Movimentos Sociais e 3) Gestão Pública e Desenvolvimento Local.

Na Dimensão da Agenda de Pesquisa local sugerem-se alguns pontos de pauta considerados relevantes, dentre os quais podem ser destacados os estudos voltados para: 1) elucidar as estruturas de poder local, envolvendo análise sobre as estratégias de obtenção e manutenção de poder das elites políticas; 2 ) perceber as configurações dos blocos ideológico-partidários locais, analisando as relações e posicionamentos dos partidos e lideranças no campo políticoeleitoral; 3) verificar as relações de pertencimento e identidade dos integrantes da sociedade macapaense com a cultura política local; 4) identificar os traços e características das estratégias de desenvolvimento local declaradas e implementadas pelas administrações municipais, visando perceber continuidades e rupturas; 5) analisar as características das estruturas e dinâmicas das Instituições Participativas e suas efetividades na implantação de políticas públicas locais em suas diversas fases de desenvolvimento; 6) perceber as relações entre em- poderamento e estratégias participativas de desenvolvimento de políticas públicas; 7) analisar os efeitos das tensões entre atores nas arenas de conflito de interesses que se configuram no campo político local; e 8) descortinar configurações e processos de mobilização de capital social no desenvolvimento das políticas públicas locais.

Ao finalizar esta trajetória ressalta-se que há sempre novos desafios a enfrentar, os quais impulsionam o ato de caminhar em direção ao conhecimento, fazendo com que se perceba o quanto é necessário dar um passo a mais. E nesse passo a mais acolhese o claro sentimento de que percursos subsequentes de produção de saberes sobre os processos de participação social no desenvolvimento das políticas locais necessitam ser trilhados e novos horizontes explorados e expandidos.

\section{REFERÊNCIAS}

ABU-EL-HAJ, Jawdat. Robert Dahl (19152014): poder político, liberalização e contestação nas democracias. Revista Brasileira de Ciência Política, v. 4, 2014, p. 7-17. ABU-EL-HAJ, Jawdat. A mobilização do capital social no Brasil: O caso da reforma sanitária no Ceará. São Paulo: Editora Annablume, 1999.

AVRITZER, Leonardo. Instituições participativas e desenho institucional: algumas considerações sobre a variação da participação social no Brasil democrático. Opinião Pública, Campinas, v. 14, n.1, 2008, p. 43-64. Disponível em: <http://www.scielo.br/pdf/ op/v14n1/02.pdf>. Acesso em: 15 mar. 2013.

AVRITZER, Leonardo. Participatory institutions in democratic Brazil. Baltimore: The Johns Hopkins University Press, 2009a. 
BARCELLOS, Annibal. Discurso proferido na 110a Sessão da Assembléia Nacional Constituinte, em 24 de julho de 1987. Diário da Assembleia Nacional Constituinte. Brasília, 25 jul. 1987, p. 3582-3583. Disponível em: <http://imagem.camara.gov.br/Imagem/d/ pdf/104anc25jul1987.pdf\#page $=>$ Acesso em: 12 jun. 2016.

BARDACH, Eugene. A practical guide for policy analysis. Loss Angeles: Sage, 2012 BOURDIEU, Pierre. O capital social: notas provisórias. In: NOGUEIRA, Maria Alice; CATANI, Afrânio (Orgs.). Escritos de Educação. 11. ed. Petrópolis: Editora Vozes, 2010.

BREWER, Gary; DELEON, Peter. The Foundations of Policy Analysis. Monterey, Cal.: Brooks, Cole,1983.

CHILCOTE, Ronald. Theories of Comparative Politics. Boulder: Westview, 1981.

CORTES, Soraya Vargas. As diferentes instituições participativas existentes nos municípios brasileiros. In: PIRES, Roberto Rocha C. Efetividade das instituições participativas no Brasil: estratégias de avaliação. Brasília: IPEA, 2011. p.137-149. Disponível em: $<$ http://desafios2.ipea.gov.br/participacao/i mages/pdfs/livro_efetividade.pdf>. Acesso em: 12 fev. 2014.

DAHL, Robert. A Preface to Economic Democracy. New Haven: Yale University Press, 1985.

DAHL, Robert. Dilemmas of Pluralist Democracy: Autonomy vs. Control. 1983.

DAHL, Robert. How democratic is the American constitution. New Haven: Yale University Press, 2003.

DE ALMEIDA, Candido Mendes. Atlas do Império do Brasil: comprehendendo as respectivas divisões administrativas, eclesiásticas, eleitorais e judiciais. Rio de Janeiro: Lithographia do Instituto Philomathico,
1868. Disponível em: <http://www2.sena do.leg.br/bdsf/item/id/179473>. Acesso em: 12 abr. 2016.

DE ALMEIDA, Candido Mendes. Pinsonia: elevação do território septentrional da Província do Grão-Pará à categoria de Província com essa denominação. Rio de Janeiro: Nova Typographia de João Paulo Hildebrant, 1873. Disponível em: <http://www2.sena do.leg.br/bdsf/item/id/221695>. Acesso em: 12 abr. 2016.

DOWNS, Anthony. An economic theory of democracy. New York: Harper, 1957.

EASTON, David. The Political System: an inquiry into the state of political science. New York: Alfred and Knopfe, 1953.

EASTON, David. A systems analysis of political life. New York: John Wiley and Sons, 1965.

EMMETT, Ross B., ed. The Elgar Companion to the Chicago School of Economics. Cheltenham: Edward Elgar, 2010

FERRAREZI, Elisabete. Capital social: conceitos e contribuições às políticas públicas. Revista do Serviço Público, v. 54, n.4, p. 722, 2003. Disponível em: <http://seer.enap. gov.br/index.php/RSP/article/view/273/279 >. Acesso em: 20 jun. 2015.

GALINDO, Alexandre Gomes. Participação social no desenvolvimento de políticas públicas no Estado ao Amapá: um olhar sobre a elaboração e execução do Plano plurianual de Macapá-AP no período de 2013 a 2016. 2017. 305 f. Tese (Doutorado em Sociologia). Centro de HumanidadesDepartamento de Ciências Sociais, Universidade Federal do Ceará, Fortaleza-CE, 2017. Disponível em: <www.repositorio.ufc. br/bitstream/riufc/22337/1/2017_tese_agg alindo.pdf>. Acesso em: 09 abr. 2017. HABERMAS, Jurgen. Structural Transformation of the Public Sphere. Cambridge, 
Mass: MIT Press, 1989.

HABERMAS, Jurgen. The public sphere: an encyclopedia article (1964). New German Critique, no. 3, Autumn, 1974, p. 49-55.

HABERMAS, Jurgen. Theory of Communicative Action, Volume 1. Boston: Beacon Press, 1983.

HABERMAS, Jurgen. Theory of Communicative Action, Volume 2. Boston: Beacon Press, 1987.

HALL, Peter; TAYLOR, Rosemary. As três versões do neo-institucionalismo. Lua Nova, no. 58,2003 , p. 193-223.

HOVENKAMP, Herbert. Antitrust Policy after Chicago. Michigan Law Review v. 84, n. 2, 1985, p. 213-284.

JANOSKI, Thomas et al. The Handbook of Political Sociology: States, Civil Societies, and Globalization. Cambridge: Cambridge University Press, 2005.

KASPER, Sherryl. The Revival of LaissezFaire in American Macroeconomic Theory: A Case Study of Its Pioneers. Cheltenham: Edward Elgar, 2002.

LASSWELL, Charles. Politics: Who Gets What, When, How? New York: MacGrawHill, 1936.

LIJPHART, Arend. 'Typologies of Democratic Systems', Comparative Political Studies $v$. 1, 1968, p. 3-44.

LIJPHART, Arend. Consociational Democracy. World Politics, v. 2, 1969, p. 207-225.

LIJPHART, Arend. Patterns of Democracy: Government Forms and Performance in Thirty-Six Countries. New Haven: Yale University Press, 1999.

LINDBLOM Charles. Politics and markets: the world's political-economic systems. New York: Basic Books, 1977.

LINDBLOM Charles. The market system: what it is, how it works, and what to make of it. New Haven: Yale University Press,
2001.

LINDBLOM Charles. The science of muddling through. Public Administration Review v. 19 , no. 2, 1959, p. 79-88.

MOUFFE, Chantal. Agonistics: Thinking The World Politically. London - New York: Verso, 2013.

MOUFFE, Chantal. Dimensions of Radical Democracy: Pluralism, Citizenship, Community. London - New York: Verso, 1992.

MOUFFE, Chantal. The Return of the Political. London-New York: Verso, 1993 NISKANEN, William. Bureaucracy and Representative Government. Chicago \& New York: Aldine-Atherton, Inc, 1971.

NUNES, Coaracy Gentil Monteiro. Discurso proferido na 16a Sessão da Câmara de Deputados, em 6 de abril de 1949. Diário do Congresso Nacional. Brasília, 07 abr. 1949, p. 2629-2632. Disponível em: <http://ima gem.camara.gov.br/Imagem/d/pdf/DCD07A BR1949.pdf\#page $=>$ Acesso em: 12 jun. 2016.

NUNES, Janary Gentil. Discurso proferido na 33a Sessão Conjunta do Congresso Nacional, em 14 de janeiro de 1967. Diário do Congresso Nacional. Brasília, 15 jan. 1967, p. 217-219. Disponível em: <http://imagem. camara.gov.br/dc_20bCarrossel.asp?selCod ColecaoCsv=J\&Datain=15/1/1967\&txSuple mento $=\&$ txPagina $=>$ Acesso em: 12 jun. 2016.

OSTROM, Elinor. Governing the Commons: The Evolution of Institutions for Collective Action. New York: Cambridge University Press, 1990.

PATEMAN, Carole. Participation and democratic theory. Cambridge England: Cambridge University Press, 1970.

PATEMAN, Carole. The problem of political obligation: a critique of liberal theory. Cambridge: Polity, 1985. 
PORTO, Jadson Luís Rabelo. Desenvolvimento geográfico desigual da faixa de fronteira da Amazônia setentrional brasileira: reformas da condição fronteiriça amapaense (1943-2013). 2014. 163f. Relatório Pós-Doutoral (Pós-Doutorado em Desenvolvimento Regional). Departamento de Ciências Sociais e Filosofia, Universidade Regional de Blumenau, Blumenal-SC, 2014. REIS, Arthur Cezar Ferreira. Território do Amapá: perfil histórico. Rio de Janeiro: Departamento de Imprensa Nacional, 1949.

STIGLER, George. Chicago Studies in Political Economy. Chicago: University of Chicago Press, 1988.

STIGLER, George. The Theory of Economic Regulation. Bell Journal of Economics and Management Science v. 2, spring, 1971, p. 3-21.

TOSTES, José Alberto et al. O desenvolvimento local integrado entre as cidades de Macapá e Santana (Estado do Amapá, Brasil). PRACS: Revista Eletrônica de Humanidades do Curso de Ciências Sociais da UNIFAP. Macapá, v.8, n.2, 2015, p. 149-167. Disponível em: <http://periodicos.unifap. br/index.php/pracs>. Acesso em: 15 jul. 2016.

TOSTES, José Alberto; TAVARES, Ana Paula Cunha. Cidade e história na Amazônia: Fortaleza de São José de Macapá (da gênese ao simbolismo do patrimônio). In: ENCONTRO DA ASSOCIAÇÃO NACIONAL DE PESQUISA E PÓS-GRADUAÇÃO EM ARQUITETURA E URBANISMO, 3., 2014, São Paulo-SP. Anais... São Paulo-SP: Associação Nacional de Pesquisa e Pós-Graduação em Arquitetura e Urbanismo-ANPARQ, 2014. p. 1-11. Disponível em: <http://www.anparq.org.br/dvdenanparq-3/htm/Artigos/SC/ORAL/SC-PCl033_TOSTES_TAVARES.pdf > Acesso em: 15 jun. 2016.
Artigo recebido em 04 de outubro de 2017. Aprovado em 29 de novembro de 2017. 